\title{
Quantification of Dynamic ${ }^{11}$ C-Phenytoin PET Studies
}

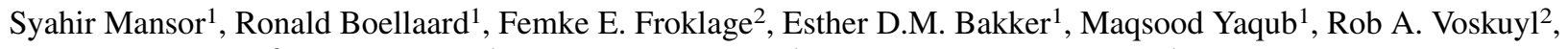 \\ Lothar A. Schwarte ${ }^{3}$, Joost Verbeek ${ }^{1}$, Albert D. Windhorst ${ }^{1}$, and Adriaan Lammertsma ${ }^{1}$

\begin{abstract}
${ }^{I}$ Department of Radiology and Nuclear Medicine, VU University Medical Center, Amsterdam, The Netherlands; ${ }^{2}$ Department of Neurology, Stichting Epilepsie Instellingen Nederland (SEIN), Heemstede, The Netherlands; and ${ }^{3}$ Department of Anaesthesiology, $V U$ University Medical Center, Amsterdam, The Netherlands
\end{abstract}

The overexpression of P-glycoprotein (Pgp) is thought to be an important mechanism of pharmacoresistance in epilepsy. Recently, ${ }^{11} \mathrm{C}$-phenytoin has been evaluated preclinically as a tracer for Pgp. The aim of the present study was to assess the optimal plasma kinetic model for quantification of ${ }^{11} \mathrm{C}$-phenytoin studies in humans. Methods: Dynamic ${ }^{11} \mathrm{C}$-phenytoin PET scans of 6 healthy volunteers with arterial sampling were acquired twice on the same day and analyzed using single- and 2-tissue-compartment models with and without a blood volume parameter. Global and regional testretest (TRT) variability was determined for both plasma to tissue rate constant $\left(K_{1}\right)$ and volume of distribution $\left(\mathrm{V}_{\mathrm{T}}\right)$. Results: According to the Akaike information criterion, the reversible single-tissue-compartment model with blood volume parameter was the preferred plasma input model. Mean TRT variability ranged from $1.5 \%$ to $16.9 \%$ for $K_{1}$ and from $0.5 \%$ to $5.8 \%$ for $\mathrm{V}_{\mathrm{T}}$. Larger volumes of interest showed better repeatabilities than smaller regions. A 45-min scan provided essentially the same $K_{1}$ and $V_{T}$ values as a $60-m i n$ scan. Conclusion: A reversible single-tissue-compartment model with blood volume seems to be a good candidate model for quantification of dynamic ${ }^{11} \mathrm{C}$-phenytoin studies. Scan duration may be reduced to $45 \mathrm{~min}$ without notable loss of accuracy and precision of both $K_{1}$ and $V_{\mathrm{T}}$, although this still needs to be confirmed under pathologic conditions.

Key Words: ${ }^{11} \mathrm{C}$-phenytoin; PET quantification; kinetic modeling; test-retest variability

J Nucl Med 2015; 56:1372-1377

DOI: 10.2967/jnumed.115.158055

$\mathbf{E}$ pilepsy is one of the most common neurologic disorders worldwide (1). Almost $30 \%$ of all patients who suffer from epilepsy do not respond to drug therapy (2). Nonresponse may be related to an overexpression of P-glycoprotein (Pgp). Pgp (3-5) is an efflux transporter, located at the blood-brain barrier, that transports substrates (including multiple central nervous system drugs) from the brain back into the blood and cerebrospinal fluid. The overexpression of Pgp is thought to be an important mechanism of pharmacoresistance in epilepsy $(6,7)$. In refractory patients, this overexpression has been confirmed by examining brain tissue postmortem or after surgical removal $(8,9)$. The development of noninvasive imaging methods that would allow

Received Mar. 22, 2015; revision accepted Jun. 23, 2015.

For correspondence or reprints contact: Syahir Mansor, Department of Radiology and Nuclear Medicine, VU University Medical Center, P.O. Box 7057, 1007MB Amsterdam, The Netherlands.

E-mail: m.mansor@vumc.nl

Published online Jul. 1, 2015.

COPYRIGHT (C 2015 by the Society of Nuclear Medicine and Molecular Imaging, Inc. for in vivo assessment of Pgp function in the brain is of great interest. Several studies have demonstrated that PET with ${ }^{11} \mathrm{C}$-radiolabeled Pgp substrates, such as $(R)-{ }^{11} \mathrm{C}$-verapamil $(3-5)$ or ${ }^{11} \mathrm{C}-\mathrm{N}$-desmethylloperamide ( ${ }^{11} \mathrm{C}$-dLop) (10), is a promising imaging tool for in vivo assessment of Pgp function in the blood-brain barrier $(7,11-13)$. Other tracers to measure Pgp expression, such as ${ }^{11} \mathrm{C}$-laniquidar $(14,15)$ and ${ }^{11} \mathrm{C}$-tariquidar $(16)$, have also been developed. These compounds are inhibitors at pharmacologic doses but act as substrates at tracer doses, and more work is needed to assess the utility of these tracers. High-affinity Pgp substrates have low brain uptake, limiting their suitability as a PET tracer for mapping regional Pgp overexpression, as this overexpression would reduce uptake even further. ${ }^{11} \mathrm{C}$-phenytoin, an antiepileptic drug, is a relatively weak Pgp substrate that is expected to show higher brain uptake, possibly resulting in PET images with better image quality. The slower washout and the fairly good stability of the tracer in plasma (as shown later) might allow for robust kinetic evaluations. The purpose of the present study was to identify a candidate model that may be used for kinetic evaluations (17). To assess Pgp in patients with pharmacoresistant epilepsy, a reliable quantification method for ${ }^{11} \mathrm{C}$-phenytoin needs to be developed. The aim of the present study was therefore to identify a potential candidate plasma input kinetic model that may be used for the quantification of ${ }^{11} \mathrm{C}$-phenytoin studies in humans and to establish its test-retest (TRT) performance.

\section{MATERIALS AND METHODS}

\section{Subjects}

Six healthy male volunteers (mean age, 28 y; age range, 21-32 y) were included. All subjects were extensively screened for medical history and underwent physical (including neurologic) examination and laboratory tests. Subjects were also screened for neurologic and psychiatric illness and history of drug abuse. Written informed consent was obtained from each subject after each was given a written and verbal description of the study. The study was approved by the Medical Ethics Review Committee of the VU University Medical Center.

\section{Imaging Procedure}

All subjects underwent 2 identical dynamic PET studies on the same day. Scans were performed on a Gemini TF PET/CT scanner (Philips). The properties of this scanner have been reported elsewhere (18). Before tracer injection, a low-dose CT scan was obtained. These data were used to correct the subsequent emission scan for photon attenuation. Next, a dynamic emission scan in 3-dimensional acquisition mode was started simultaneously with an intravenous injection of $345 \pm 54$ (mean $\pm \mathrm{SD}$ ) $\mathrm{MBq}$ of ${ }^{11} \mathrm{C}$-phenytoin with a specific activity of $72 \pm 27 \mathrm{MBq} \cdot \mu \mathrm{mol}^{-1} \cdot{ }^{11} \mathrm{C}$-phenytoin was synthesized as described previously (17). The radiotracer was provided in a total volume of $7 \mathrm{~mL}$ and administered at a rate of $0.8 \mathrm{~mL} \cdot \mathrm{s}^{-1}$, followed by a flush of $42 \mathrm{~mL}$ of saline at $2.0 \mathrm{~mL} \cdot \mathrm{s}^{-1}$ using an infusion pump (Med-Rad). 


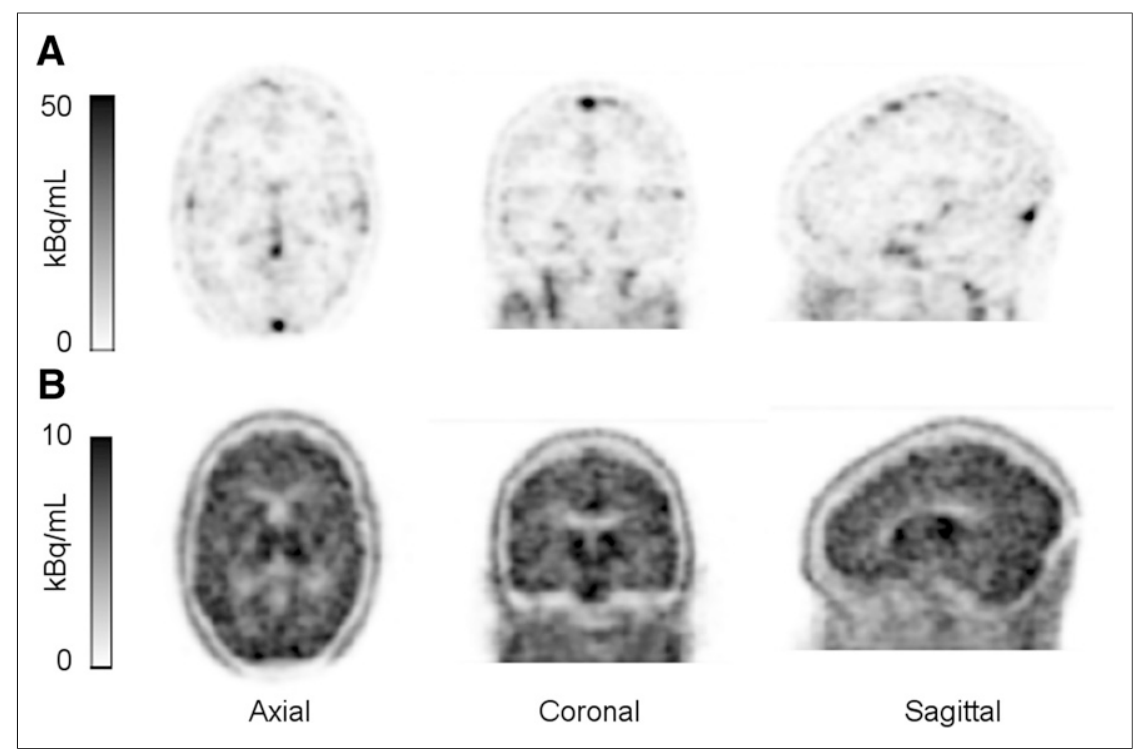

FIGURE 1. Typical ${ }^{11} \mathrm{C}$-phenytoin activity concentration images obtained in healthy subject, averaged over several early frames (30-90 s after injection) (A) and late frames (45-60 min after injection) (B).

The scan was acquired in list-mode for $60 \mathrm{~min}$. The list-mode data were later histogrammed into 20 frames with progressive increase in frame durations of $1 \times 15,3 \times 5,3 \times 10,4 \times 60,2 \times 150,2 \times 300$, and $4 \times 600 \mathrm{~s}$. During acquisition, patient movement was restricted by the use of a head holder and monitored by checking the position of the head using laser beams. All emission data were reconstructed using a line-ofresponse row-action maximum-likelihood algorithm, as provided by the scanner vendor. All corrections required for generating quantitative PET images, such as dead time, scatter, random, decay, and attenuation corrections, were applied. The image matrix size was $128 \times 128$ with 90 axial slices, resulting in a voxel size of $2 \times 2 \times 2 \mathrm{~mm}$. The reconstructed spatial resolution was approximately $5 \mathrm{~mm}$ in full width at half maximum at the center of the field of view. After image reconstruction, patient motion (which may have occurred despite the use of the head holder) was assessed and corrected by a frame-by-frame alignment of the images using VINCI software (Max Plank Institute).

During the $60-\mathrm{min}{ }^{11} \mathrm{C}$-phenytoin scan, arterial blood was withdrawn continuously using an automatic online blood sampler (Veenstra

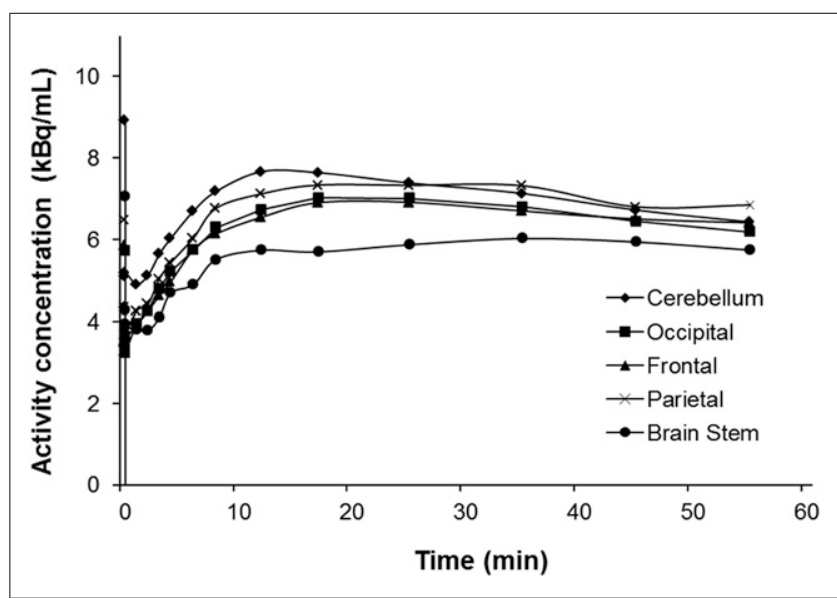

FIGURE 2. Example of decay-corrected time-activity curves of ${ }^{11} \mathrm{C}$ phenytoin for several brain regions in healthy subject.
Instruments) (19) at a rate of $5 \mathrm{~mL} \cdot \mathrm{min}^{-1}$ for the first $5 \mathrm{~min}$ and $2.5 \mathrm{~mL} \cdot \mathrm{min}^{-1}$ thereafter. At 2.5, 5, 10, 20, 30, 40, and 60 min after tracer injection, continuous blood sampling was interrupted briefly to withdraw $7 \mathrm{~mL}$ of manual blood samples. After each sample, the arterial line was flushed with a heparinized saline solution. In addition, all subjects underwent structural MR imaging using a 1.5-T Sonata scanner (Siemens Medical Solutions).

\section{Blood Analysis}

Manual samples were used to determine plasma-to-whole-blood radioactivity concentration ratios. In addition, concentrations of parent ${ }^{11} \mathrm{C}$-phenytoin and its radioactive metabolites in plasma were determined using the following procedure. One milliliter of plasma was diluted with $2 \mathrm{~mL}$ of water and passed over an activated Sep-Pak tC18 (Waters). After being rinsed with $3 \mathrm{~mL}$ of water, the cartridge was eluted with $1.5 \mathrm{~mL}$ of methanol and $1.5 \mathrm{~mL}$ of water. This eluate was vortexed and analyzed further using high-performance liquid chromatography (HPLC). The HPLC consisted of a Dionex Ultimate 3000, equipped with a 1.0-mL loop. A Phenomenex (Torrance) Gemini C18 $10 \times$

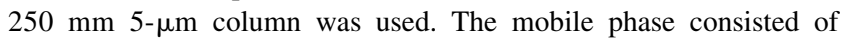
a mixture of acetonitrile and $0.1 \%$ trifluoroacetic acid in water. During analysis, a gradient was used so that the percentage of $0.1 \%$ trifluoroacetic acid in water was $90 \%$ at the start of analysis and $30 \%$ after $4 \mathrm{~min}$. Flow of the mobile phase was $4.0 \mathrm{~mL} \cdot \mathrm{min}^{-1}$.

Plasma-to-whole-blood ratios and parent fractions were used in combination with the continuously collected whole-blood input curve to generate a metabolite-corrected plasma input function. Hill functions (20) were used to fit parent fractions and plasma-to-blood ratios.

\section{Image Analysis}

First, each MR image was coregistered with the corresponding PET image using VINCI software. Next, volumes of interest (VOIs) were defined using an automated method based on a VOI template (PVElab) (21) that consisted of 67 regions covering the entire brain (22). Gray and white matter segmentation of the coregistered MR

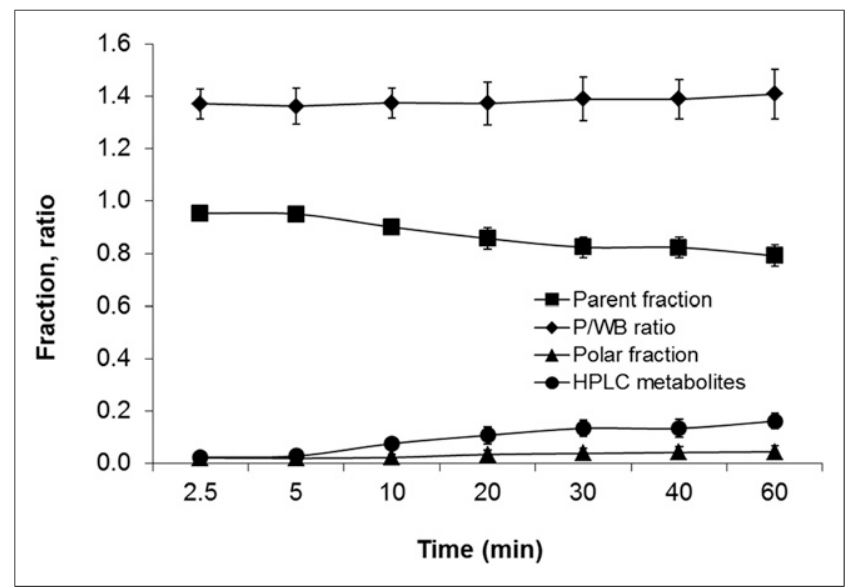

FIGURE 3. Mean and SD (error bar) of parent and polar fractions, plasma-to-whole-blood ratio (P/WB), and HPLC metabolites obtained from manual blood samples. 
TABLE 1

Preference Frequency (\%) According to Akaike Information Criteria for Small $(<5 \mathrm{~mL})$ and Large $(>5 \mathrm{~mL})$ VOI Sizes

\begin{tabular}{lcc}
\hline \multirow{2}{*}{ Model } & \multicolumn{2}{c}{ Akaike frequency $(\%)$} \\
\cline { 2 - 3 } & VOI $<5 \mathrm{~mL}$ & $\mathrm{VOI}>5 \mathrm{~mL}$ \\
\hline 1T2k & 0.0 & 0.0 \\
$1 \mathrm{~T} 2 \mathrm{k}+\mathrm{V}_{\mathrm{b}}$ & 31.3 & 42.2 \\
$2 \mathrm{~T} 3 \mathrm{k}$ & 0.0 & 0.0 \\
$2 \mathrm{~T} 3 \mathrm{k}+\mathrm{V}_{\mathrm{b}}$ & 4.6 & 13.8 \\
$2 \mathrm{~T} 4 \mathrm{k}$ & 0.0 & 0.0 \\
$2 \mathrm{~T} 4 \mathrm{k}+\mathrm{V}_{\mathrm{b}}$ & 4.9 & 3.2 \\
\hline
\end{tabular}

image was performed using statistical parametric mapping (version 8 , SPM8), which is incorporated in the PVElab software. Finally, gray matter time-activity curves were generated by projecting all VOIs onto

\section{Kinetic Analysis}

Various compartment models were tested (23), such as plasmainput single-tissue-compartment models without (1T2k) and with $\left(1 \mathrm{~T} 2 \mathrm{k}+\mathrm{V}_{\mathrm{b}}\right)$ blood volume parameter, and plasma-input 2-tissuecompartment models with irreversible $(2 \mathrm{~T} 3 \mathrm{k})$ and reversible $(2 \mathrm{~T} 4 \mathrm{k})$ kinetics, both with and without additional $\mathrm{V}_{\mathrm{b}}$. In addition, $1 \mathrm{~T} 2 \mathrm{k}$, $2 \mathrm{~T} 3 \mathrm{k}$, and $2 \mathrm{~T} 4 \mathrm{k}$ models with $\mathrm{V}_{\mathrm{b}}$ fixed to $5 \%$ were tested as well.

Models were fitted to gray matter time-activity curves using standard nonlinear regression analysis. Fitting routines were developed inhouse using Matlab software (The MathWorks). For each of the fits, the Akaike information criterion (AIC) (24) was calculated. For each time-activity curve, the preferred model was selected on the basis of the lowest AIC across all models. The frequency of AIC preferences for each model (pooled over all subjects) was then derived, and the model with the highest overall frequency was selected as the preferred model. Model preferences were evaluated separately for both small $(\leq 5 \mathrm{~mL})$ and large $(>5 \mathrm{~mL})$ VOIs. In addition, an F test $(25)$ was preferred over those with fewer. Finally, kinetic analysis was repeated for shorter scan intervals to investigate the impact of scan duration on model preference and parameter estimates and to obthe dynamic PET data. used to assess whether models with more kinetic parameters were

TABLE 2

TRT Variabilities for $K_{1}$ and $V_{\mathrm{T}}$ for Each Individual Subject, Given as Average ( $\pm S D$ ) Percentage Repeatability Across All VOls

\begin{tabular}{lrr}
\hline \multicolumn{1}{c}{ Subject } & \multicolumn{1}{c}{$K_{1}$ TRT } & \multicolumn{1}{c}{$\mathrm{V}_{\mathrm{T}} \mathrm{TRT}$} \\
\hline 1 & $4.10 \pm 4.72$ & $2.23 \pm 4.62$ \\
\hline 2 & $0.83 \pm 5.98$ & $-3.15 \pm 6.95$ \\
3 & $8.76 \pm 4.50$ & $1.53 \pm 6.01$ \\
4 & $-6.13 \pm 7.71$ & $-3.42 \pm 6.78$ \\
5 & $-17.6 \pm 7.24$ & $-2.99 \pm 13.8$ \\
6 & $6.51 \pm 4.44$ & $-2.46 \pm 3.70$ \\
Average \pm SD & $-0.59 \pm 10.73$ & $-1.38 \pm 8.00$ \\
\hline
\end{tabular}

tain an estimate of the minimally required scan duration for reliable quantification.

\section{TRT Variability}

After kinetic analysis, TRT variability of all kinetic parameters was calculated. TRT variability was calculated as the difference between test and retest kinetic parameters divided by their mean times $100 \%$. The Student $t$ test was used to assess the impact of different scan durations and VOI size on TRT of the plasma to tissue rate constant $\left(K_{1}\right)$ and volume of distribution $\left(\mathrm{V}_{\mathrm{T}}\right)$. Moreover, Bland-Altman plots (26) of the kinetic parameters were generated to illustrate differences between test and retest values.

\section{RESULTS}

\section{PET Image and Blood Data Analysis}

A typical ${ }^{11} \mathrm{C}$-phenytoin uptake image, averaged over the frames collected from 25 to $90 \mathrm{~s}$ after injection and averaged over frames from 45 to $60 \mathrm{~min}$ after injection are shown in Figure 1, illustrating the distribution of ${ }^{11} \mathrm{C}$-phenytoin uptake at different uptake intervals throughout the brain. Time-activity curves for several regions of interest are shown in Figure 2. Various fits for the whole-brain gray matter time-activity curve are shown in Supplemental Figure 1 (supplemental materials are available at http://jnm.snmjournals.org). Average plasma-to-whole-blood ratios, parent fractions, and polar and nonpolar metabolite fractions are presented in Figure 3. The plasma-towhole-blood ratio was relatively constant
A

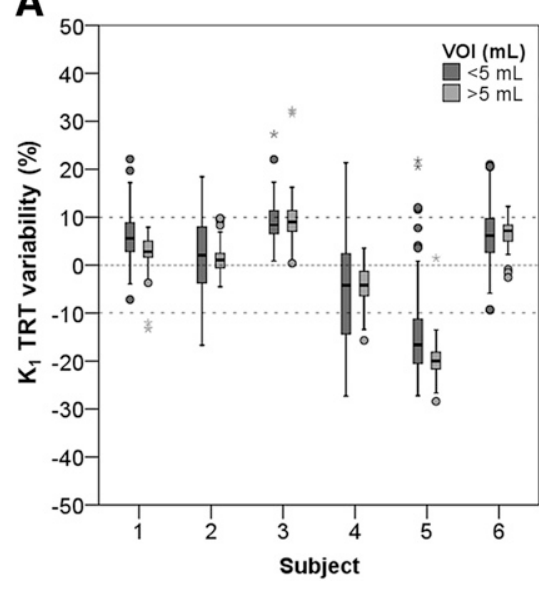

B

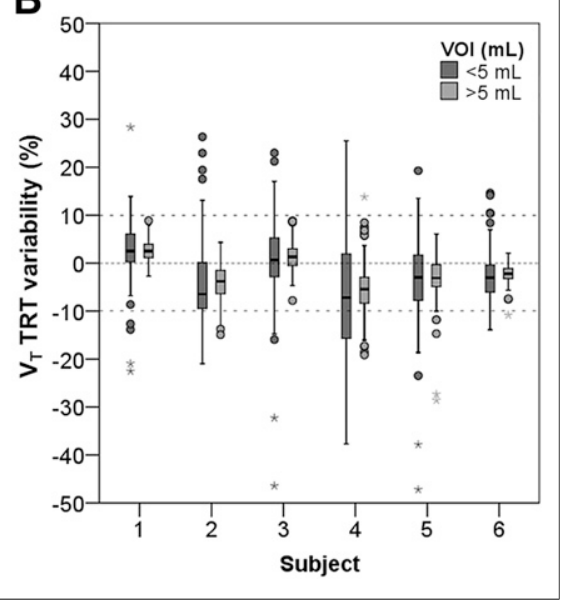

FIGURE 4. TRT variability of $K_{1}(\mathrm{~A})$ and $\mathrm{V}_{\mathrm{T}}(\mathrm{B})$ for each subject for small $(<5 \mathrm{~mL})$ and large $(>5 \mathrm{~mL})$ region-of-interest volumes. over time, ranging from about 1.3 to 1.4. The parent fraction of ${ }^{11} \mathrm{C}$-phenytoin in plasma slowly decreased to $79 \% \pm 4 \%$ at $60 \mathrm{~min}$, whereas nonpolar and polar metabolite fractions increased from $2.3 \% \pm$ $2.1 \%$ and $2.1 \% \pm 1.8 \%$ at $2.5 \mathrm{~min}$ to $16.1 \% \pm 3.1 \%$ and $4.4 \% \pm 2.2 \%$ at 60 min, respectively. At present, these radiolabeled metabolites have not yet been characterized.

\section{Compartmental Modeling}

Four of the 6 compartment models fitted both test and retest data well. AIC preference percentages are shown in Table 1 for both test and retest scans. As can be seen, the $1 \mathrm{~T} 2 \mathrm{k}+\mathrm{V}_{\mathrm{b}}$ model was preferred in most cases, followed by $2 \mathrm{~T} 3 \mathrm{k}+\mathrm{V}_{\mathrm{b}}$ and $2 \mathrm{~T} 4 \mathrm{k}+\mathrm{V}_{\mathrm{b}}$ models. This preference was 
TABLE 3

Summary of Correlation Parameters Between Data from Different Scan Durations (45 and 30 Minutes) Versus 60 Minutes

\begin{tabular}{|c|c|c|c|c|c|c|c|c|}
\hline \multirow[b]{3}{*}{ Scan duration } & \multicolumn{4}{|c|}{$K_{1}$} & \multicolumn{4}{|c|}{$\mathrm{V}_{\mathrm{T}}$} \\
\hline & \multicolumn{2}{|c|}{ Test } & \multicolumn{2}{|c|}{ Retest } & \multicolumn{2}{|c|}{ Test } & \multicolumn{2}{|c|}{ Retest } \\
\hline & Slope & $R^{2}$ & Slope & $R^{2}$ & Slope & $R^{2}$ & Slope & $R^{2}$ \\
\hline 45 vs. $60 \mathrm{~min}$ & 1.00 & 0.98 & 1.00 & 0.98 & 1.00 & 0.84 & 1.00 & 0.90 \\
\hline 30 vs. $60 \mathrm{~min}$ & 1.02 & 0.97 & 1.00 & 0.98 & 0.98 & 0.76 & 0.99 & 0.86 \\
\hline
\end{tabular}

seen regardless of the volume of the VOIs as shown in Table 1. $A V_{b}$ was required for all models tested. This model was preferred across all subjects studied for each individual regionthat is, we could not identify a specific region with a different preference. Although models with a fixed blood volume fraction of $5 \%$ were also evaluated, the $1 \mathrm{~T} 2 \mathrm{k}+\mathrm{V}_{\mathrm{b}}$ model using $\mathrm{V}_{\mathrm{b}}$ as fit parameter was still preferred. AIC preferences were confirmed by $\mathrm{F}$ test scores that showed that for more than $60 \%$ of the time-activity curve the simpler model $\left(1 \mathrm{~T} 2 \mathrm{k}+\mathrm{V}_{\mathrm{b}}\right)$ was favored over more complicated ones. In Supplemental Figure 2, $K_{1}$ and $\mathrm{V}_{\mathrm{T}}$ data are given for various regions across the brain. As can be seen, $K_{1}$ and $\mathrm{V}_{\mathrm{T}}$ values are reasonably comparable across the gray matter regions shown and correspond to the distributions seen in the early and late uptake images shown in Figure 1.

\section{TRT Repeatability}

Figure 4 shows box plots of percentage differences between test and retest scans for $K_{1}$ and $\mathrm{V}_{\mathrm{T}}$ values, respectively, obtained using the $1 \mathrm{~T} 2 \mathrm{k}+\mathrm{V}_{\mathrm{b}}$ model. Results are provided per patient for both small $(\leq 5 \mathrm{~mL})$ and large $(>5 \mathrm{~mL})$ VOIs. In general, the median percentage differences between test and retest studies were about $10 \%$, except for subject 5 who showed up to $20 \%$ of TRT variability for $K_{1}$ (Fig. 4A). A somewhat wider range (larger interquartile range) in TRT variability of both $K_{1}$ and $\mathrm{V}_{\mathrm{T}}$ (Fig. 4B) was observed for small compared with large VOIs, but this difference is not statistically significant ( $t$ test, $P>0.05$ ). Individual TRT variabilities are provided in Table 2.

\section{Impact of Scan Duration}

Supplemental Figure 3 shows fair to good correlations of 1T2k + $\mathrm{V}_{\mathrm{b}}$-derived $K_{1}$ and $\mathrm{V}_{\mathrm{T}}$ values for shorter scan durations (45 and $30 \mathrm{~min}$ ) with those obtained for 60 -min scans. In the case of $K_{1}$, the correlation was slightly better for 45- than for 30-min data for both test and retest scans (Supplemental Figs. 3A and 3B). The same was true for $\mathrm{V}_{\mathrm{T}}$, although the difference between 45 and 30 min was larger (Supplemental Figs. 3C and 3D). Although there were fair to good correlations between 45- and 30-min data and those of $60 \mathrm{~min}$, a significant difference in the correlation of $\mathrm{V}_{\mathrm{T}}$ was seen when the scan duration was reduced to $30 \min (P<$ $0.05)$. Table 3 shows the summary information of correlation between different scan durations.

TRT data are shown as Bland-Altman plots in Figure 5, and percentage TRT repeatability for individual patients is shown in Figure 6 for both $K_{1}$ (Fig. 6A) and $\mathrm{V}_{\mathrm{T}}$ (Fig. 6B). It can be seen that shortening the scan duration from 60 to $45 \mathrm{~min}$ did not substantially affect the TRT variability of $K_{1}$ and $\mathrm{V}_{\mathrm{T}}$.

\section{DISCUSSION}

Compared with previous preclinical studies in rats (17), the metabolism of ${ }^{11} \mathrm{C}$-phenytoin in humans was relatively slow, with $79 \%$ of the original tracer still intact at $60 \mathrm{~min}$ after injection. The parent fraction was higher than that of other, more avid Pgp substrates, such as $(R)-{ }^{11} \mathrm{C}$-verapamil, with $50 \%$ intact parent tracer at $60 \mathrm{~min}$ (27). In addition, parent fractions of ${ }^{11} \mathrm{C}$-phenytoin were comparable across subjects, as indicated by the small variability (SD) shown in Figure 3. This small intersubject variability and the slow metabolism of ${ }^{11} \mathrm{C}$-phenytoin may allow for the use of a plasma input function without additional metabolite analysis, for example, using a population average approach for the parent fraction. However, this approach was not (yet) evaluated because of the small number of subjects and it should also be noted that ${ }^{11} \mathrm{C}$-phenytoin metabolism may be affected by treatment or be different in patients. Variability in tracer metabolism first needs to be investigated under these conditions before population-based approaches can be used. Nevertheless, ${ }^{11} \mathrm{C}$-phenytoin seems to have a favorable metabolic profile.

In this study, we evaluated a possible suitable candidate model to analyze ${ }^{11} \mathrm{C}$-phenytoin kinetics. Among various models investigated, the single-tissue-compartment model with 2 kinetic parameters and an additional blood volume fraction parameter was the preferred plasma input model in $60 \%-70 \%$ of cases (Table 1).

Moreover, this model was preferred across all subjects studied for each individual region, and it is therefore the model of choice for quantification of dynamic ${ }^{11} \mathrm{C}$ phenytoin studies. The preference for the $1 \mathrm{~T} 2 \mathrm{k}+\mathrm{V}_{\mathrm{b}}$ model was more pronounced than in the case of $(R)-{ }^{11} \mathrm{C}$-verapamil, where it was preferred in only $15 \%$ of the cases (27). The preference for a model with a limited number of fit parameters in combination with slow tracer metabolism in plasma suggests that robust quantification of ${ }^{11} \mathrm{C}$-phenytoin studies is feasible. Feasibility was confirmed by the observed good TRT performances, as discussed later.

The present study was performed to identify a possible suitable candidate plasma input kinetic model for ${ }^{11} \mathrm{C}$-phenytoin and,
FIGURE 5. Bland-Altman plots of $K_{1}(\mathrm{~A}-\mathrm{C})$ and $\mathrm{V}_{\mathrm{T}}(\mathrm{D}-\mathrm{F})$ test-retest data for $60-(\mathrm{A}$ and $\mathrm{D}), 45-(\mathrm{B}$ and $\mathrm{E})$, and 30- (C and F) min scan durations. $O=60$-min scan duration data; $\square=45$-min scan duration data; $\triangle=30$-min scan duration data; bold line $=$ mean difference between test and retest. 


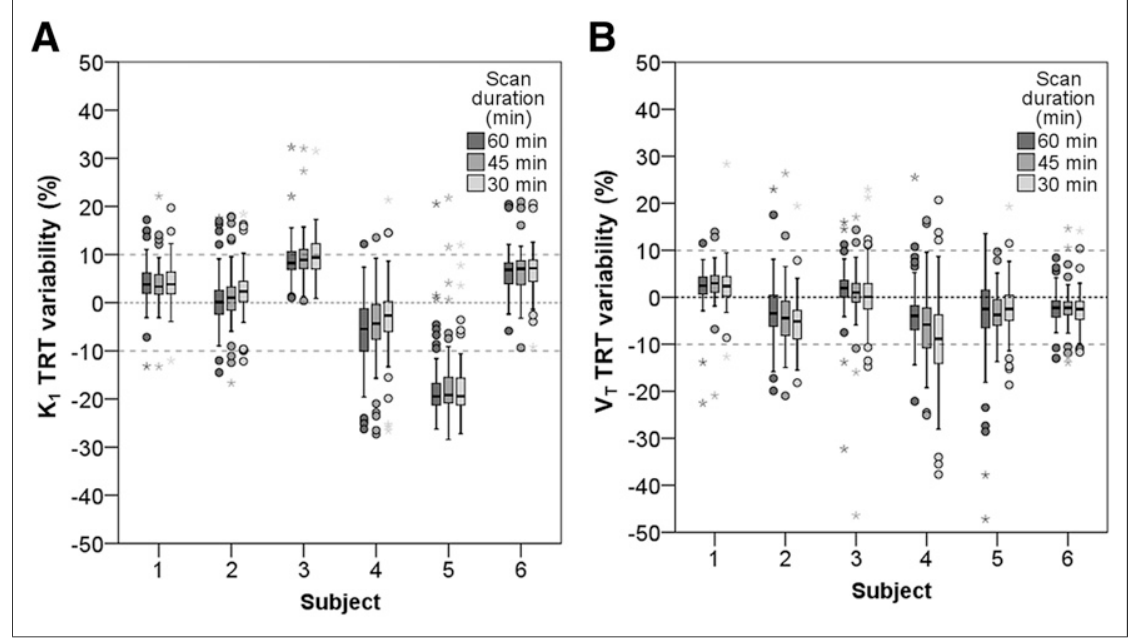

FIGURE 6. TRT variability of $K_{1}(\mathrm{~A})$ and $\mathrm{V}_{\mathrm{T}}(\mathrm{B})$ for each subject and for different scan durations.
It can be concluded that ${ }^{11} \mathrm{C}$-phenytoin dynamic PET studies in healthy subjects can be performed using 45-min scan durations without significantly affecting accuracy and TRT performance of both $K_{1}$ and $\mathrm{V}_{\mathrm{T}}$ estimates. However, for patients and for studies after pharmacologic blocking of Pgp or during treatment, the washout of ${ }^{11} \mathrm{C}$-phenytoin may be reduced or tracer metabolism might be different and longer scan durations may still be required, which need to be clarified in future studies.

Results of this first-in-human PET study showed good agreement with observations of a previous preclinical study (17). In particular, the present study confirmed good tracer characteristics of ${ }^{11} \mathrm{C}$-phenytointhat is, high metabolic stability in plasma and robust kinetics, with a maximum brain uptake approximately $20 \mathrm{~min}$ after bolus

subsequently, to test its performance with respect to repeatability using test and retest scans in healthy subjects. In general, TRT repeatability of $K_{1}$ and $\mathrm{V}_{\mathrm{T}}$ was small-that is, on average within $10 \%$-and comparable with that seen for $(R)-{ }^{11} \mathrm{C}$-verapamil (27). TRT of $K_{1}$ of subject 5 , however, equaled about $17 \%$. This particular case could be explained by a lower parent fraction during the initial part $(5 \mathrm{~min}$ ) of the PET scan for only 1 of the scans. When the parent fraction was set to a higher value (i.e., equal to the average of all other subjects), TRT variability improved to within $10 \%$. The observed poor $K_{1}$ TRT of about $17 \%$ of this subject seems therefore to be caused by a measurement error in the parent fraction. Larger regions of interest $(>5 \mathrm{~mL})$ showed a smaller interquartile range for TRT than smaller regions of interest, but this difference was not significant ( $t$ test, $P>0.05$ ). Because compartmental model analysis is sensitive to noise, an increase in TRT can be expected when using smaller regions of interest.

Reducing the scan duration to 45 or 30 min resulted in $V_{T}$ estimates that were similar to those obtained from the entire $60 \mathrm{~min}$ of data, with somewhat higher correlation coefficients for the 45-min data (Figs. 6C and 6D). In addition, for none of the subjects TRT performances of both $K_{1}$ and $\mathrm{V}_{\mathrm{T}}$ were substantially affected by changing scan duration. However, there was a significant difference in $\mathrm{V}_{\mathrm{T}}$ TRT $(P<0.05)$ for 30 - versus 60-min data. Yet, TRT variability was, on average, less than $10 \%$ for both $\mathrm{V}_{\mathrm{T}}$ and $K_{1}$ in most subjects. injection. Results from the present study also indicate that ${ }^{11} \mathrm{C}$ phenytoin has slower ingrowth of labeled metabolites in plasma and a higher $\mathrm{V}_{\mathrm{T}}$ than $(R)-{ }^{11} \mathrm{C}$-verapamil (28). $K_{1}$ was similar to that of $(R)-{ }^{11} \mathrm{C}$-verapamil and 3 -fold higher than that of ${ }^{11} \mathrm{C}$-dLop (10). In addition, the efflux rate $\left(k_{2}\right)$ of ${ }^{11} \mathrm{C}$-phenytoin was approximately $60 \%$ lower than that of $(R)-{ }^{11} \mathrm{C}$-verapamil $(28)$ and about 4-fold higher than that of ${ }^{11} \mathrm{C}$-dLop. However, $k_{2}$ values of the various tracers cannot be directly compared with each other because of the use of different kinetic models. $\mathrm{V}_{\mathrm{T}}$ of ${ }^{11} \mathrm{C}$-phenytoin was found to be approximately $25 \%$ lower than that of ${ }^{11} \mathrm{C}$-dLop and $30 \%$ higher than that of $(R)-{ }^{11} \mathrm{C}$-verapamil. The distribution of $\mathrm{V}_{\mathrm{T}}$ of ${ }^{11} \mathrm{C}$-phenytoin was fairly uniform across the various gray matter brain regions and comparable to that seen with $(R)-{ }^{11} \mathrm{C}$ verapamil. A summary of various kinetic parameters is presented in Table 4. Among the 3 presented tracers, ${ }^{11} \mathrm{C}$-phenytoin seems to demonstrate a high first-pass extraction fraction (by the fairly high $K_{1}$ values), resulting in high tracer brain uptake and intermediatehigh $\mathrm{V}_{\mathrm{T}}$, because of the low $k_{2}$ values, and low plasma metabolism, which might explain the robust kinetic analysis and good TRT performances seen so far.

In the present study the kinetic properties of ${ }^{11} \mathrm{C}$-phenytoin were assessed, and a possible suitable candidate model for quantitative analysis was established. Nevertheless, further studies will be needed to assess whether ${ }^{11} \mathrm{C}$-phenytoin is a useful tracer and whether the preferred candidate model is suitable for investigating

TABLE 4

Comparison of Some Kinetic Parameters for ${ }^{11} \mathrm{C}$-Phenytoin, $(R)-{ }^{11} \mathrm{C}$-Verapamil, and ${ }^{11} \mathrm{C}$-dLop

\begin{tabular}{cccc}
\hline \multicolumn{1}{c}{ Pgp substrate } & $K_{1}\left(\mathrm{~mL} \cdot \mathrm{mL}^{-1} \cdot \mathrm{min}^{-1}\right)$ & $k_{2}\left(\mathrm{~min}^{-1}\right)$ & $\mathrm{V}_{\mathrm{T}}\left(\mathrm{mL} \cdot \mathrm{mL}^{-1}\right)$ \\
\hline${ }^{11} \mathrm{C}$-phenytoin $(n=6)^{\star \dagger}$ & $0.037 \pm 0.008$ & $0.042 \pm 0.009$ & $0.881 \pm 0.126$ \\
$(R)-{ }^{11} \mathrm{C}$-verapamil $(n=5)^{\ddagger}$ & $0.036 \pm 0.009$ & $0.102 \pm 0.003$ & $0.660 \pm 0.123$ \\
${ }^{11} \mathrm{C}$-dLop $(n=6)^{\star}$ & $0.014 \pm 0.001$ & $0.012 \pm 0.002$ & $1.169 \pm 0.149$ \\
\hline
\end{tabular}

*Obtained using $1 \mathrm{~T} 2 \mathrm{k}+\mathrm{V}_{\mathrm{b}}$ model.

${ }^{\dagger}$ Pooled over whole-brain region across all subjects.

${ }^{\ddagger}$ Obtained using $2 \mathrm{~T} 4 \mathrm{k}$ model.

Data are mean \pm SD. 
Pgp function under pathologic conditions. Moreover, PET studies using a Pgp inhibitor, such as with high doses of laniquidar or tariquidar, could be performed to assess whether ${ }^{11} \mathrm{C}$-phenytoin PET can measure and quantify changes in Pgp function. The TRT data from the present study will be of relevance for interpretation of those intervention studies.

\section{CONCLUSION}

${ }^{11} \mathrm{C}$-phenytoin kinetics seem to be well represented by a plasma-input, single-tissue-compartment model with an additional fitted blood volume fraction parameter. Yet, this finding remains to be verified under pathologic conditions. ${ }^{11} \mathrm{C}$-phenytoin is stable in plasma, with about $80 \%$ of intact tracer at $1 \mathrm{~h}$ after injection. Scan durations can be reduced to $45 \mathrm{~min}$ without notable loss in accuracy and precision, although this needs to be validated under pathologic conditions or during treatment. Observed TRT performances for $K_{1}$ and $\mathrm{V}_{\mathrm{T}}$ are comparable to those seen with various other tracers $(<10 \%$, on average).

\section{DISCLOSURE}

The costs of publication of this article were defrayed in part by the payment of page charges. Therefore, and solely to indicate this fact, this article is hereby marked "advertisement" in accordance with 18 USC section 1734 . This work was supported by the European Union Seventh Framework Program EURIPIDES (FP7/ 2007-2013 under grant agreement no. 201380). Additional support was provided by a scholarship from the Malaysian Ministry of Education and University Sains Malaysia. No other potential conflict of interest relevant to this article was reported.

\section{REFERENCES}

1. Chang BS, Lowenstein DH. Epilepsy. N Engl J Med. 2003;349:1257-1266.

2. Kwan P, Brodie MJ. Early identification of refractory epilepsy. $N$ Engl J Med. 2000;342:314-319.

3. Bart J, Willemsen AT, Groen HJ, et al. Quantitative assessment of P-glycoprotein function in the rat blood-brain barrier by distribution volume of $\left[{ }^{11} \mathrm{C}\right]$ verapamil measured with PET. Neuroimage. 2003;20:1775-1782.

4. Sasongko L, Link JM, Muzi M, et al. Imaging P-glycoprotein transport activity at the human blood-brain barrier with positron emission tomography. Clin Pharmacol Ther. 2005;77:503-514.

5. Syvänen S, Blomquist G, Sprycha M, et al. Duration and degree of cyclosporin induced P-glycoprotein inhibition in the rat blood-brain barrier can be studied with PET. Neuroimage. 2006;32:1134-1141.

6. Dombrowski SM, Desai SY, Marroni M, et al. Overexpression of multiple drug resistance genes in endothelial cells from patients with refractory epilepsy. Epilepsia. 2001;42:1501-1506.

7. Langer O, Bauer M, Hammers A, et al. Pharmacoresistance in epilepsy: a pilot PET study with the P-glycoprotein substrate R- $\left[{ }^{11}\right.$ C $]$ verapamil. Epilepsia. 2007;48: 1774-1784.
8. Sisodiya SM, Lin WR, Harding BN, et al. Drug resistance in epilepsy: expression of drug resistance proteins in common causes of refractory epilepsy. Brain. 2002;125:22-31.

9. Feldmann M, Asselin MC, Liu J, et al. P-glycoprotein expression and function in patients with temporal lobe epilepsy: a case-control study. Lancet Neurol. 2013; 12:777-785

10. Kreisl WC, Liow JS, Kimura N, et al. P-glycoprotein function at the blood-brain barrier in humans can be quantified with the substrate radiotracer ${ }^{11} \mathrm{C}-\mathrm{N}$-desmethylloperamide. J Nucl Med. 2010;51:559-566.

11. Bankstahl JP, Kuntner C, Abrahim A, et al. Tariquidar-induced P-glycoprotein inhibition at the rat blood-brain barrier studied with $(R)-{ }^{11} \mathrm{C}$-verapamil and PET. J Nucl Med. 2008;49:1328-1335.

12. Liow JS, Kreisl W, Zoghbi SS, et al. P-glycoprotein function at the blood-brain barrier imaged using ${ }^{11} \mathrm{C}-\mathrm{N}$-desmethyl-loperamide in monkeys. $\mathrm{J} \mathrm{Nucl} \mathrm{Med}$. 2009;50:108-115.

13. Seneca N, Zoghbi SS, Liow JS, et al. Human brain imaging and radiation dosimetry of ${ }^{11} \mathrm{C}-\mathrm{N}$-desmethyl-loperamide, a PET radiotracer to measure the function of P-glycoprotein. J Nucl Med. 2009;50:807-813.

14. Luurtsema G, Schuit RC, Klok RP, et al. Evaluation of $\left[{ }^{11} \mathrm{C}\right]$ laniquidar as a tracer of P-glycoprotein: radiosynthesis and biodistribution in rats. Nucl Med Biol. 2009;36:643-649.

15. Moerman L, Dumolyn C, Boon $\mathrm{P}$, et al. The influence of mass of $\left[{ }^{11} \mathrm{C}\right]$-laniquidar and $\left[{ }^{11} \mathrm{C}\right]-\mathrm{N}$-desmethyl-loperamide on P-glycoprotein blockage at the bloodbrain barrier. Nucl Med Biol. 2012;39:121-125.

16. Bauer F, Kuntner C, Bankstahl JP, et al. Synthesis and in vivo evaluation of $\left[{ }^{11} \mathrm{C}\right]$ tariquidar, a positron emission tomography radiotracer based on a third-generation P-glycoprotein inhibitor. Bioorg Med Chem. 2010;18:5489-5497.

17. Verbeek J, Eriksson J, Syvanen S, et al. $\left[{ }^{11} \mathrm{C}\right]$ phenytoin revisited: synthesis by $\left[{ }^{11} \mathrm{C}\right] \mathrm{CO}$ carbonylation and first evaluation as a P-gp tracer in rats. EJNMMI Res. 2012;2:36-46.

18. Surti S, Kuhn A, Werner ME, et al. Performance of Philips Gemini TF PET/CT scanner with special consideration for its time-of-flight imaging capabilities. $J$ Nucl Med. 2007;48:471-480.

19. Boellaard R, van Lingen A, van Balen SC, Hoving BG, Lammertsma AA. Characteristics of a new fully programmable blood sampling device for monitoring blood radioactivity during PET. Eur J Nucl Med. 2001;28:81-89.

20. Gunn RN, Sargent PA, Bench CJ, et al. Tracer kinetic modeling of the 5-HT1A receptor ligand [carbonyl- ${ }^{11} \mathrm{C}$ ]WAY-100635 for PET. Neuroimage. 1998;8:426-440.

21. Svarer C, Madsen K, Hasselbalch SG, et al. MR-based automatic delineation of volumes of interest in human brain PET images using probability maps. Neuroimage. 2005;24:969-979.

22. Hammers A, Koepp MJ, Free SL, et al. Implementation and application of a brain template for multiple volumes of interest. Hum Brain Mapp. 2002;15:165-174.

23. Gunn RN, Gunn SR, Turkheimer FE, et al. Positron emission tomography compartmental models: a basis pursuit strategy for kinetic modeling. J Cereb Blood Flow Metab. 2002;22:1425-1439.

24. Akaike H. A new look at the statistical model identification. IEEE Trans Automat Contr. 1974; 19:716-723.

25. Cunningham VJ. Non-linear regression techniques in data analysis. Med Inform (Lond). 1985;10:137-142.

26. Bland JM, Altman D. Statistical methods for assessing agreement between two methods of clinical measurement. Lancet. 1986;1:307-310.

27. Lubberink M, Luurtsema G, van Berckel BN, et al. Evaluation of tracer kinetic models for quantification of P-glycoprotein function using (R)-[ $\left.{ }^{11} \mathrm{C}\right]$ verapamil and PET. J Cereb Blood Flow Metab. 2007;27:424-433.

28. Bauer M, Zeitlinger M, Karch R, et al. Pgp-mediated interaction between (R)$\left[{ }^{11} \mathrm{C}\right]$ verapamil and tariquidar at the human blood-brain barrier: a comparison with rat data. Clin Pharmacol Ther. 2012;91:227-233. 